\title{
A continuous-flow external ventricular assist device for cardiogenic shock: Evolution over 10 years
}

Masahiko Ando, MD, PhD, MPH, ${ }^{\mathrm{a}}$ Arthur R. Garan, MD, ${ }^{\mathrm{b}}$ Hiroo Takayama, MD, PhD,

Veli K. Topkara, MD, ${ }^{\mathrm{b}}$ Jiho Han, BS, ${ }^{\mathrm{a}}$ Paul Kurlansky, MD, ${ }^{\mathrm{a}}$ Melana Yuzefpolskaya, MD, ${ }^{\mathrm{b}}$

Maryjane A. Farr, MD, ${ }^{b}$ Paolo C. Colombo, MD, ${ }^{b}$ Yoshifumi Naka, MD, PhD, ${ }^{a}$ and Koji Takeda, MD, PhD

\begin{abstract}
Background: The use of percutaneous mechanical circulatory support (MCS) in the treatment of cardiogenic shock has increased. However, limitations in flow capability, ventricular unloading effect, durability, and mobility remain. We reviewed our single-center experience with continuous-flow external ventricular assist devices (VADs) to determine the role of temporary VADs for cardiogenic shock in the contemporary MCS era.
\end{abstract}

Methods: We retrospectively reviewed 252 patients who underwent continuousflow external VAD insertion between January 2007 and December 2016. To investigate the change in indications, device configurations, and outcomes, we divided the cohort into 2 groups-2007 to 2011 (Era 1; $n=127$ ) and 2012 to 2016 (Era 2; $\mathrm{n}=125$ ) —and compared early and late outcomes.

Results: Indications and device configurations changed significantly over time. The use of preoperative percutaneous MCS $(53 \%$ vs $23 \% ; P<.01)$ and use of minimally invasive VAD configurations $(23 \%$ vs $6.7 \% ; P<.01)$ were greater in Era 2 compared with Era 1. The rate of bridge to the next destinations, including myocardial recovery, transplantation, and durable VAD, was similar in the 2 groups. In-hospital mortality was significantly better in Era $2(50 \%$ vs $37 \%$; $P=.04)$. Overall survival at 1 year was $57 \%$ in Era 2 versus $43 \%$ in Era 1 $(P=.04)$.

Conclusions: Better outcomes in the recent era could be associated with the changes in practice patterns using continuous-flow external VAD in patients with refractory cardiogenic shock. (J Thorac Cardiovasc Surg 2018;156:157-65)

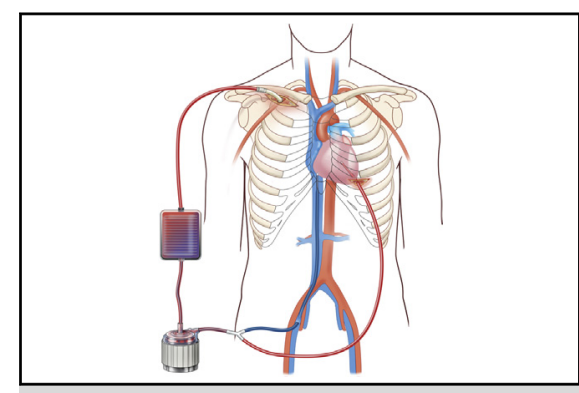

Minimally invasive ventricular assist system with oxygenator (Ec-VAD).

\section{Central Message}

Flexibility in the use of both percutaneous mechanical circulatory support and continuousflow external ventricular assist devices could improve early and late outcomes in cardiogenic shock.

\section{Perspective}

Mechanical circulatory support therapy for cardiogenic shock has evolved. This study demonstrates the usefulness of continuous-flow external ventricular assist devices for patients in cardiogenic shock at a single high-volume center. The results will allow better strategy in selection and treatment for patients in cardiogenic shock.

See Editorial Commentary page 166

See Editorial page 156.
The use of percutaneous mechanical circulatory support (MCS) for treating acute hemodynamic decompensation and refractory cardiogenic shock has expanded rapidly. ${ }^{1,2}$ Various types of percutaneous MCS have been developed,

\footnotetext{
From the ${ }^{\mathrm{a}}$ Division of Cardiothoracic Surgery, Department of Surgery, and ${ }^{\mathrm{b}}$ Division of Cardiology, Department of Medicine, Columbia University Medical Center, New York, NY.

Read at the 97th Annual Meeting of The American Association for Thoracic Surgery, Boston, Massachusetts, April 29-May 3, 2017.

Received for publication May 18, 2017; revisions received Dec 7, 2017; accepted for publication Dec 30, 2017; available ahead of print March 3, 2018.

Address correspondence to: Koji Takeda, MD, PhD, 177 Fort Washington Ave, New York, NY 10032 (E-mail: kt2485@cumc.columbia.edu). $0022-5223 / \$ 36.00$

Copyright (c) 2018 by The American Association for Thoracic Surgery https://doi.org/10.1016/j.jtcvs.2017.12.148
}

including venoarterial extracorporeal membrane oxygenation (ECMO) and the Impella system (Abiomed, Danvers, Mass), and clinical outcomes continue to improve with these new technologies. ${ }^{1,2}$ Nonetheless, there remain limitations, especially with regard to power, durability, requirement of special skill for insertion, and patient mobility after implantation. ${ }^{2}$

(4) Scanning this QR code will take
you to the supplemental figure.
To view the AATS Annual
Meeting Webcast, see the
URL next to the webcast
thumbnail.




$\begin{aligned} \text { Abbreviations and } & \text { Acronyms } \\ \text { APTT } & \text { activated partial thromboplastin } \\ & \text { time } \\ = & \text { biventricular assist device } \\ = & \text { extracorporeal membrane } \\ & \text { oxygenation } \\ = & \text { mini left ventricular assist device } \\ & \text { with extracorporeal membrane } \\ & \text { oxygenation } \\ \text { Ec-VAD } & \text { Interagency Registry for } \\ & \text { Mechanically Assisted Circulatory } \\ & \text { Support } \\ \text { INTERMACS } & \text { left ventricular assist device } \\ = & \text { mechanical circulatory support } \\ = & \text { right ventricular assist device } \\ \text { LVAD } & \text { ventricular assist device }\end{aligned}$

Because of these limitations, the role of surgical shortterm MCS has remained constant. The use of the CentriMag continuous-flow external ventricular assist device (VAD; Abbott, Pleasanton, Calif) is an attractive option for treating patients in shock. ${ }^{3}$ This pump can generate $10 \mathrm{~L} / \mathrm{min}$ of continuous flow at a low rotational speed of $5500 \mathrm{rpm}$. Various types of cannulas can be connected to the CentriMag system. These features facilitate easy insertion procedure, a flexible configuration, combined use with an oxygenator, midterm use, and easy postoperative maintenance.

In this report, we summarize our 10-year experience with continuous-flow external VAD to evaluate how the role of short-term surgical VAD for cardiogenic shock in the contemporary MCS era has been changing over time. The objective of the present study is to clarify the association between the outcomes of refractory cardiogenic shock and temporal institutional practice changes by era, such as shock etiologies, surgical indications, and treatment strategies, including VAD configurations.

\section{METHODS}

We retrospectively reviewed our experience with continuous-flow external VAD at Columbia Presbyterian Medical Center between January 2007 and December 2016. During this period, 252 consecutive patients with various etiologies of cardiogenic shock underwent continuous-flow external VAD placement as a bridge to decision therapy. To investigate the annual changes in indications, device configurations, and outcomes, the cohort was divided into 2 equal periods by the day of continuousflow external VAD placement: from January 1, 2007, to December 31, 2011 (Era 1; $\mathrm{n}=127$ ) and from January 1, 2012, to December 31, 2016 (Era 2; $\mathrm{n}=125$ ). Our Institutional Review Board approved this study.

\section{Indications and Surgical Technique}

All patients underwent continuous-flow external VAD as a bridge to decision therapy. Our algorithm for a bridge to decision device therapy for cardiogenic shock has been described previously. ${ }^{3}$ A patient with cardiogenic shock is characterized by (1) systolic blood pressure $<90 \mathrm{mmHg}$, a cardiac index $<2.0 \mathrm{~L} / \mathrm{min} / \mathrm{m}^{2}$, a pulmonary capillary wedge pressure $>16 \mathrm{mmHg}$ (or evidence of pulmonary edema in the absence of a pulmonary artery catheter), and end-organ failure, or (2) the inability to be weaned from cardiopulmonary bypass. These patients are rapidly evaluated by our multidisciplinary team. Since 2015, a "Shock Team" consisting of surgeons, cardiologists, nurse practitioners, and intensive care physicians has played a role in determining the most suitable MCS for each patient. In our institution, percutaneous MCS, such as ECMO, has gained popularity as a first rescue device over the years. As a result, continuous-flow external VAD has become a second bridge device to the final destination. Figure 1 shows the percentage of patients who were transitioned from percutaneous MCS to continuous-flow external VAD each year.

The implantation technique for conventional external VAD has been reported previously. ${ }^{3}$ We have developed several techniques for minimally invasive cannulation without cardiopulmonary bypass; the implantation technique has been described previously. ${ }^{4-6}$ For patients who need biventricular unloading, the femoral venous component of ECMO is integrated with a mini-LVAD to unload the right ventricle (Ec-VAD; Figure 2, B). Apical and femoral venous cannulas are connected with a Y-connector, and an oxygenator (Quadrox D; Maquet, Wayne, NJ) is spliced into the circuit. Since 2015, Ec-VAD has been our standard approach instead of BiVAD via sternotomy.

\section{Postimplantation Device Management}

Intravenous heparin is initiated at $300 \mathrm{U} /$ hour once tube drainage becomes serosanguinous. Activated partial thromboplastin time (APTT) is measured every 8 hours. Heparin dose is titrated to target APTT at 60 to 80 seconds. Once the patient's condition begins to improve, as marked by acceptable hemodynamics, lactate clearance, end-organ function improvement, and stable neurologic condition, cardiac function is challenged through device weaning. The weaning protocol was reported previously. ${ }^{3}$ Weaning is generally performed in intensive care units with a Swan-Ganz catheter. In brief, with therapeutic APTT, flows are reduced to $1 \mathrm{~L} / \mathrm{min}$. Maintenance of stable hemodynamics (central venous pressure $<13 \mathrm{mmHg}$, mean arterial pressure $>65 \mathrm{mmHg}$, pulmonary capillary wedge pressure $<18 \mathrm{mmHg}$, cardiac index $>2.2 \mathrm{~L} / \mathrm{min} / \mathrm{m}^{2}$ ) ensures appropriate ventricular functions. In patients with Ec-VAD, the flow of femoral venous limb is gradually weaned to $1.5 \mathrm{~L} / \mathrm{min}$, and then the

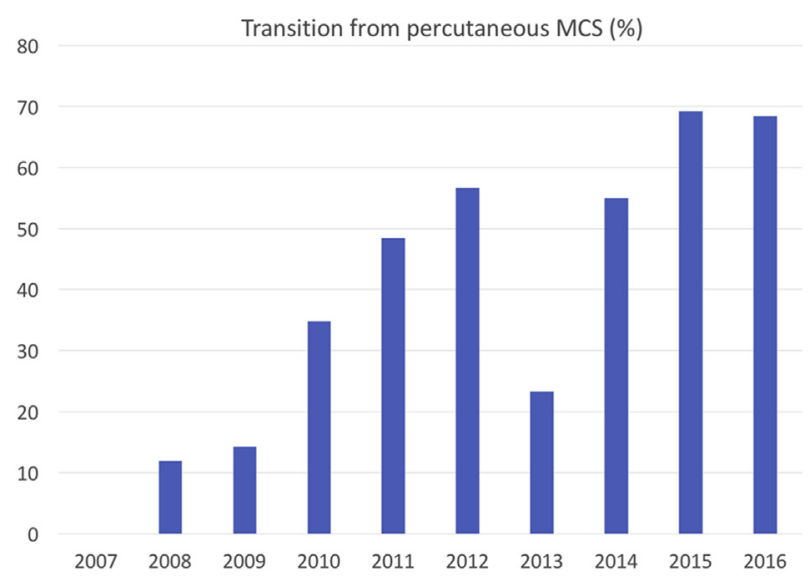

FIGURE 1. Trend of percutaneous mechanical circulatory support use before continuous-flow external ventricular assist device implantation. MCS, Mechanical circulatory support. 


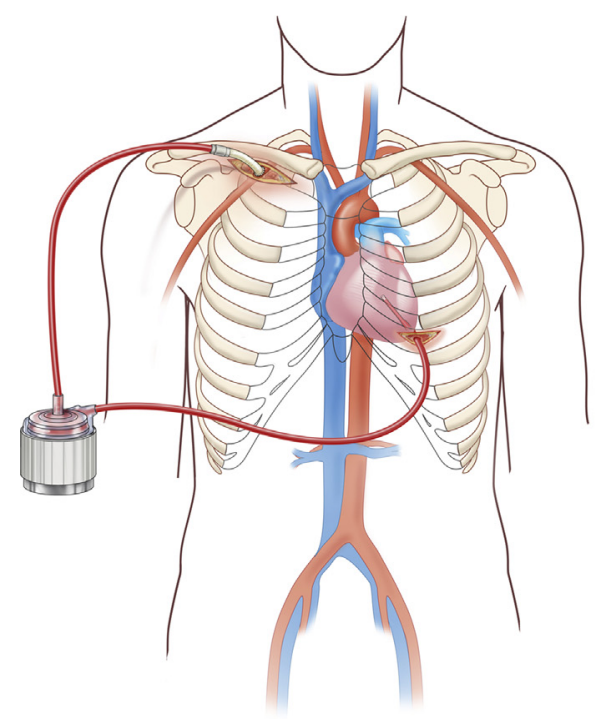

A

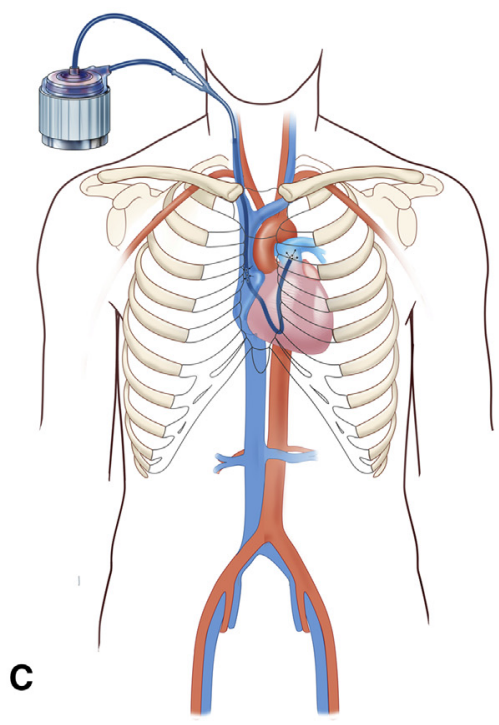

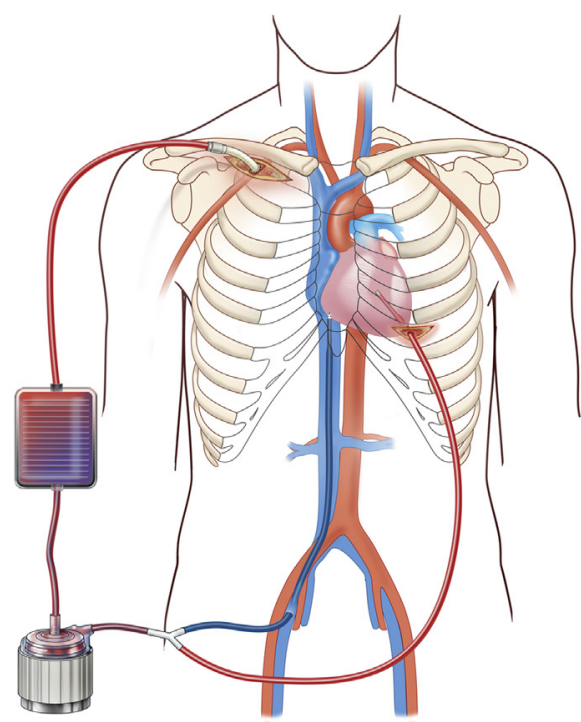

B

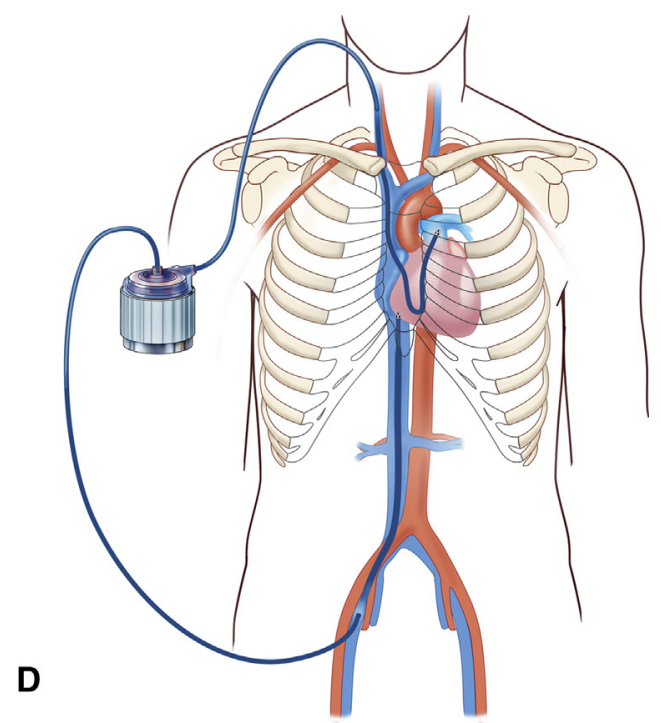

FIGURE 2. A-D, Various minimally invasive external ventricular assist device configurations.

limb is temporarily clamped at bedside as a final assessment. If the above parameters are met, the venous limb and oxygenator are removed, and Ec-VAD is converted to mini-LVAD. If a patient cannot tolerate femoral venous weaning, the venous limb is switched to the jugular vein for patient mobility. ${ }^{4}$ According to the weaning test, the device is explanted to one of the following destinations: exchange to durable VAD, explantation if there is sufficient myocardial recovery, or explantation for heart transplantation.

\section{Data Collection and Follow-up}

Preoperative variables included age, sex, shock etiology, comorbidities including diabetes and hypertension, previous percutaneous MCS, and laboratory test results (Table 1). Intraoperative variables included the use of cardiopulmonary bypass and the configuration of the continuous-flow external VAD (Table 2). Postoperative data included duration of support, incidence of complications, and outcomes, including recovery, transition to durable support, transplantation, and death (Table 3). Follow-up was completed in $100 \%$ of patients on January 31, 2017.

\section{Statistical Analysis}

Statistical analyses were performed using R version 3.4.2 (R Foundation for Statistical Computing, Vienna, Austria). Categorical variables are expressed as frequencies and percentages and compared using Fisher's exact test. Continuous variables are expressed as median with interquartile range and compared using the Mann-Whitney $U$ test. Kaplan-Meier curves were used to represent survival and were compared using the log-rank test. Univariable and multivariable Cox regression analyses were performed to identify factors significantly associated with hazard of death after external VAD implantation. A stepwise selection algorithm was used for multivariable model building to minimize the Akaike information criterion. Missing variables were replaced by multiple imputation with predictive mean matching. For all analyses, a $P$ value $<.05$ was considered statistically significant. 
TABLE 1. Baseline characteristics

\begin{tabular}{|c|c|c|c|}
\hline Characteristic & Era 1 & Era 2 & $P$ value \\
\hline Number of patients & 127 & 125 & \\
\hline Age, y, median (IQR) & $56.0(45.0-63.0)$ & $58.0(47.0-65.0)$ & .436 \\
\hline Body mass index, $\mathrm{kg} / \mathrm{m}^{2}$, median (IQR) & $27.0(23.6-32.2)$ & $27.4(24.7-31.3)$ & .421 \\
\hline Body surface area, $\mathrm{m}^{2}$, median (IQR) & $1.97(1.80-2.12)$ & $1.97(1.81-2.12)$ & .793 \\
\hline Female, n (\%) & $40(31.5)$ & $41(32.8)$ & .931 \\
\hline Hypertension, n (\%) & $65(51.2)$ & $70(56.0)$ & .452 \\
\hline Diabetes mellitus, n (\%) & $39(30.7)$ & $44(35.2)$ & .503 \\
\hline Hyperlipidemia, n (\%) & $48(37.8)$ & $49(47.2)$ & .161 \\
\hline Previous stroke, n (\%) & $6(4.7)$ & $12(9.6)$ & .149 \\
\hline Previous myocardial infarction, $\mathrm{n}(\%)$ & $42(33.1)$ & $34(27.2)$ & .338 \\
\hline $\begin{array}{l}\text { Etiology of shock, } \mathrm{n}(\%) \\
\text { Acute myocardial infarction } \\
\text { Postcardiotomy shock } \\
\text { Acute decompensated chronic heart failure } \\
\text { Graft failure after heart transplantation } \\
\text { RV failure after durable LVAD insertion } \\
\text { Myocarditis } \\
\text { Others }\end{array}$ & $\begin{array}{c}32(25.2) \\
31(24.4) \\
29(22.8) \\
20(15.8) \\
6(4.7) \\
6(4.7) \\
3(2.4)\end{array}$ & $\begin{array}{c}36(28.8) \\
24(19.2) \\
30(24.0) \\
12(9.6) \\
16(12.8) \\
6(4.8) \\
1(0.8)\end{array}$ & .190 \\
\hline Preoperative IABP, n (\%) & $67(52.8)$ & $55(44.0)$ & .234 \\
\hline $\begin{array}{l}\text { Preoperative percutaneous MCS, n (\%) } \\
\text { ECMO } \\
\text { Impella } \\
\text { ECMO and Impella } \\
\text { TandemHeart }\end{array}$ & $\begin{array}{c}29(22.8) \\
22 \\
4 \\
2 \\
1\end{array}$ & $\begin{array}{c}66(52.8) \\
41 \\
6 \\
18 \\
1\end{array}$ & $<.001$ \\
\hline Preoperative ventilator support, $\mathrm{n}(\%)$ & $81(63.8)$ & $85(68.0)$ & .508 \\
\hline Preoperative CVVH, n (\%) & $22(17.3)$ & $15(12.1)$ & .287 \\
\hline Total protein, g/dL, median (IQR) & $5.4(4.7-6.3)$ & $5.5(4.6-6.4)$ & .626 \\
\hline Albumin-g/dL, median (IQR) & $3.1(2.7-3.6)$ & $3.0(2.6-3.5)$ & .248 \\
\hline Blood urea nitrogen, mg/dL, median (IQR) & $25.0(19.0-37.0)$ & $29.0(17.0-42.0)$ & .463 \\
\hline Creatinine, mg/dL, median (IQR) & $1.4(1.1-1.8)$ & $1.5(1.1-2.3)$ & .326 \\
\hline WBC, $\times 1000 / m L$, median (IQR) & $12.6(8.4-17.3)$ & $12.6(8.5-17.7)$ & .948 \\
\hline Hemoglobin, g/dL, median (IQR) & $10.2(9.1-12.2)$ & $10.2(9.0-12.3)$ & .890 \\
\hline Hematocrit, \%, median (IQR) & $30.2(26.5-36.1)$ & $28.7(25.1-32.9)$ & .089 \\
\hline Platelets, ×1000/mL, median (IQR) & $159.0(101.5-210.0)$ & $144.0(79.0-215.0)$ & .479 \\
\hline Total bilirubin, mg/dL, median (IQR) & $1.6(0.9-3.0)$ & $1.2(0.8-2.2)$ & .055 \\
\hline Direct bilirubin, mg/dL, median (IQR) & $0.5(0.3-1.6)$ & $0.4(0.2-1.0)$ & .073 \\
\hline AST, U/L, median (IQR) & $99.0(42.0-367.0)$ & $81.0(33.0-281.0)$ & .196 \\
\hline ALT, U/L, median (IQR) & $53.0(24.5-161.0)$ & $45.0(20.0-128.0)$ & .409 \\
\hline PT-INR, median (IQR) & $1.4(1.2-1.8)$ & $1.3(1.2-1.6)$ & .042 \\
\hline Lactate, mmol/L, median (IQR) & $2.9(1.4-7.2)$ & $1.8(1.4-2.7)$ & $<.001$ \\
\hline
\end{tabular}

$I Q R$, Interquartile range; $R V$, right ventricle; $L V A D$, left ventricular assist device; $I A B P$, intra-aortic balloon pump; $M C S$, mechanical circulatory support; $E C M O$, extracorporeal membrane oxygenation; $C V V H$, continuous veno-venous hemofiltration; $W B C$, white blood cell; $A S T$, aspartate transaminase; $A L T$, alanine transaminase; $P T-I N R$, prothrombin time international normalized ratio. 
TABLE 2. Intraoperative variables

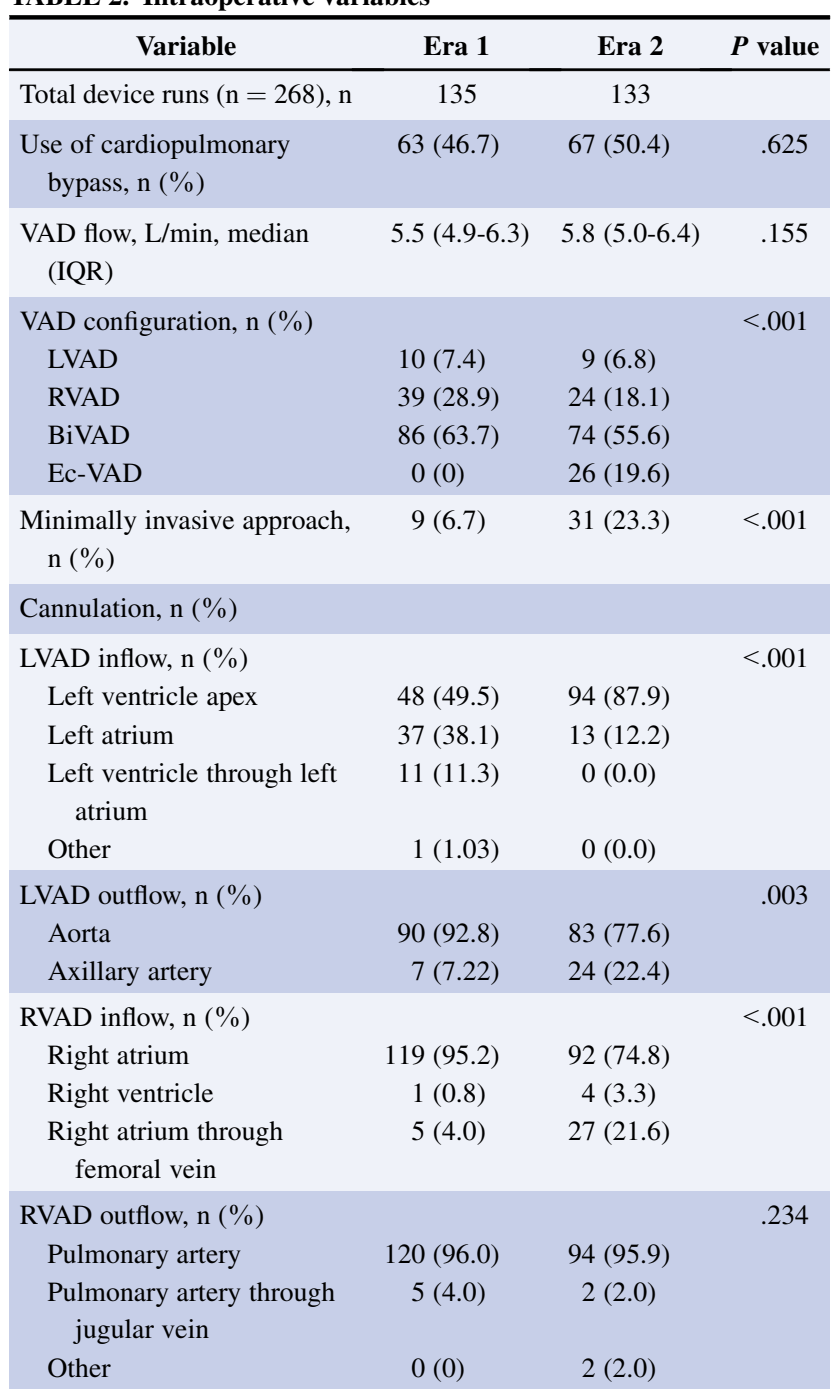

$V A D$, Ventricular assist device; $I Q R$, interquartile range; $L V A D$, left ventricular assist device; $R V A D$, right ventricular assist device; $B i V A D$, biventricular assist device; $E c$ $V A D$, ventricular assist device integrated with extracorporeal membrane oxygenation.

\section{RESULTS}

\section{Baseline Characteristics}

A total of 252 patients received continuous-flow external VAD support, with a total of 268 device runs. Baseline data for Eras 1 and 2 are summarized in Table 1. Patients in Era 2 had a significantly higher rate of preoperative use of percutaneous MCS. ECMO was the most predominant percutaneous MCS used in both eras. Serum lactate level was significantly lower in Era 2 patients. Other laboratory variables were similar in the 2 groups.

\section{Intraoperative Variables}

Table 2 summarizes the intraoperative outcomes among 268 device runs. The cardiopulmonary bypass was used similarly in both groups. BiVAD was the most common configuration in both eras, whereas Ec-VAD was used only in Era 2. A minimally invasive approach was more frequently used in Era 2. Accordingly, the cannulation strategy changed significantly over time. The majority of patients in Era $2(88 \%)$ received apical cannulation as an LVAD inflow. Peripheral cannulation, such as axillary arterial or femoral venous cannulation, was more frequently used as LVAD outflow and RVAD inflow in Era 2.

\section{Early Clinical Outcomes}

In the entire cohort, 67 patients $(27 \%)$ died during device support (median, 18 days; interquartile range, 10-33). Eighty-six patients $(34 \%)$ could wean from device support after adequate recovery of ventricular function. Thirty-one $(12 \%)$ were bridged to heart transplantation, and 54 $(21 \%)$ were transitioned to a durable VAD. In entire cohort, 30 -day mortality was $27 \%$. During the index hospitalization, 109 in-hospital deaths $(43 \%)$ occurred.

Early clinical outcomes in the 2 groups are compared in Table 3 . The median duration of support was significantly longer in Era 2 (20 vs 15 days; $P=.016$ ). Eighty-eight patients $(70 \%)$ in Era 2 reached the next destination (myocardial recovery in 45 [36\%], device exchange to a durable $\mathrm{VAD}$ in 31 [25\%], and heart transplantation in 12 [9.6\%]), compared with 83 patients $(65 \%)$ in Era 1 (myocardial recovery in 41 [32\%], device exchange to a durable VAD in 23 [18\%], and heart transplantation in 19 $[15 \%] ; P=.42)$. In-hospital mortality was significantly better in Era 2 compared with Era 1 (37\% vs 50\%; $P=.042$ ). Incidences of stroke, bleeding, and sepsis/bacteremia during support were similar in the 2 groups.

Figure 3 compares in-hospital mortality according to shock etiology in the 2 groups. Mortality was highest in patients with postcardiotomy shock in both eras. There was a statistically significant tendency toward reduced mortality over time in patients with acute myocardial infarction (44\% in Era 1 vs $25 \%$ in Era $2 ; P=.085)$ and those with myocarditis $(50 \%$ in Era 1 vs $0 \%$ in Era $2 ; P=.091)$.

\section{Late Clinical Outcomes and Risk Factors for Overall Mortality}

The 1-year overall survival in the 2 eras is compared in groups Figure 4, $A$. The 1-year survival rate was significantly better in Era $2(43 \%$ vs $57 \% ; P=.043)$. Because the patients with isolated RVADs had different etiologies than the patients with other external VADs, we stratified the entire cohort by isolated RVAD or not (Figure 4,B). The 1-year survival rates in both the isolated RVAD cohort and the entire cohort without isolated RVAD were better in Era 2, albeit not significantly so (isolated RVAD: 43\% vs $61 \%, P=.227$; all but isolated RVAD: $43 \%$ vs $56 \%$, $P=.106)$. In the entire cohort, 121 patients (48\%) died during the 1-year follow-up period. Cox proportional hazard analysis in the entire cohort was performed to elucidate the risk factors for overall death (Table 4). In this analysis, 
TABLE 3. Early outcomes

\begin{tabular}{llll}
\hline \multicolumn{1}{c}{ Outcome } & \multicolumn{1}{c}{ Era 1 } & \multicolumn{1}{c}{ Era 2 } & P value \\
\hline Number of patients & 127 & 125 & \\
Days of support, median (IQR) & $15(8-28)$ & $20(12-39)$ & .016 \\
\hline Death on device, n (\%) & $37(29.1)$ & $30(24.0)$ & .394 \\
Recovery (weaned off device), & $41(32.3)$ & $45(36.0)$ & .596 \\
$\quad$ n (\%) & & & \\
Heart transplant, n (\%) & $19(15.0)$ & $12(9.60)$ & .250 \\
Durable LVAD, n (\%) & $23(18.1)$ & $31(24.8)$ & .221 \\
Others, n (\%) & $6(4.7)$ & $7(5.6)$ & .784 \\
Morbidity during support, n (\%) & & & \\
$\quad$ Stroke & $20(15.7)$ & $21(16.8)$ & .956 \\
$\quad \begin{array}{l}\text { Major and minor bleeding } \\
\text { Sepsis/bacteremia }\end{array}$ & $95(74.8)$ & $86(68.8)$ & .358 \\
\hline IQR, Interuatie rang; $L V A D$, left vention & $19(15.0)$ & $21(16.8)$ & .820 \\
\hline
\end{tabular}

$I Q R$, Interquartile range; $L V A D$, left ventricular assist device.

older age, female sex, and higher preoperative serum lactate, total bilirubin, and creatinine concentrations were identified as independent risk factors.

\section{DISCUSSION}

A major finding of this study is that treatment of patients with cardiogenic shock using continuous-flow external VAD has evolved, and significantly better early and late outcomes were seen in Era 2. These better outcomes in the more recent era could be related to various practical changes in our institution over the 10-year study period.

Mortality in patients with cardiogenic shock remains high. There is growing interest in MCS therapy to improve outcomes. ${ }^{1,2}$ Recent advances in technology now enable treatment of shock patients with various percutaneous MCS devices. Comparison of baseline demographic data for the 2 eras (Table 1 and Figure 1) clearly represent current trends in MCS therapy for cardiogenic shock. Patients

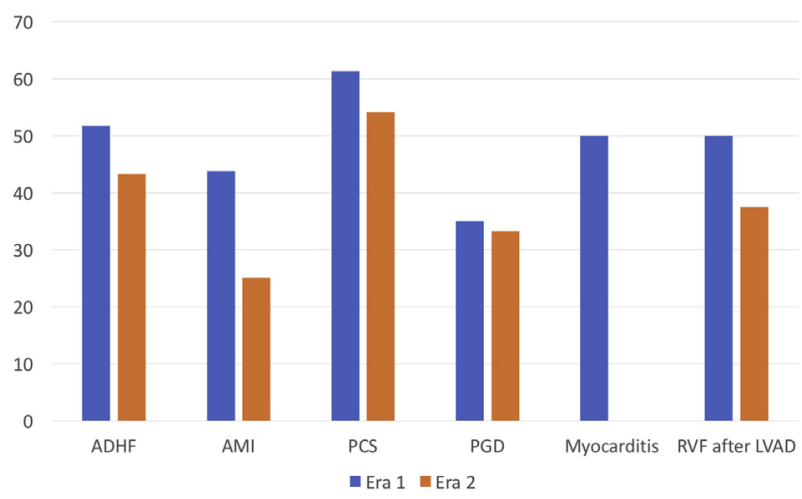

FIGURE 3. Comparison of in-hospital mortality stratified by etiology of shock. $A D H F$, Acute decompensated heart failure; $A M I$, acute myocardial infarction; $P C S$, postcardiotomy shock; $P G D$, primary graft dysfunction; $R V F$, right ventricular failure; $L V A D$, left ventricular assist device. with greater acuity and severity tend to be treated with percutaneous MCS. In our program, we prefer to use venoarterial ECMO because of easy insertion and the ability to provide high-flow circulatory support. ${ }^{3,7}$ Our multivariable analysis showed that end-organ failure as well as rising lactate levels had significant impacts on worse midterm survival. This finding suggests that restoring tissue perfusion before end-organ dysfunction is a key aspect of MCS therapy for these patients. One challenge is the time-sensitive nature of this illness. In that sense, ECMO is the fastest way to stabilize a patient and prevent endorgan failure, because it can be implanted even at bedside. In fact, patients in Era 2 had significantly lower lactate levels compared with those in Era 1. However, traditional femoral veno-arterial ECMO is limited by adverse hemodynamics due to increases in afterload with left ventricular loading rather than unloading. Other major limitations of femoral veno-arterial ECMO include the patient's immobility and the durability of the configuration, especially when combined with other percutaneous MCS devices, such as the Impella, for ventricular unloading. ${ }^{8}$ Moreover, veno-arterial ECMO requires the use of an oxygenator in its circuit, which may be associated with platelet consumption and clotting issues. ${ }^{9}$ Other percutaneous MCSs also have inherent limitations. ${ }^{2}$

We have reported the use of external VAD using the CentriMag pump to treat patients in cardiogenic shock. ${ }^{3-6}$ Our present results further solidify the role of this approach as a second bridge to decision tool in the contemporary percutaneous MCS era. It can overcome the drawbacks of percutaneous MCS by providing flexible configurations, a direct ventricular unloading effect, and prolonged circulatory support with ambulatory rehabilitation. External VAD, which is essentially a left-heart bypass, also allows for earlier weaning off the oxygenator compared with a veno-arterial ECMO configuration.

For patients with predominant left ventricular failure, the question always rises of whether to place a durable LVAD from percutaneous MCS without a second bridge by CentriMag support. However, all shock patients do not necessarily need a durable LVAD, as our present results show. Furthermore, the outcomes of durable LVAD implantation are known to be poor in patients with Interagency Registry for Mechanically Assisted Circulatory Support (INTERMACS) profile $\mathrm{I}^{10} \mathrm{~A}$ recent study found a significantly high 90-day mortality of $39 \%$ in patients with INTERMACS profile I. ${ }^{11}$ We previously reported a favorable bridge to a durable LVAD outcome with $18 \%$ in-hospital mortality in INTERMACS I patients. ${ }^{10}$ Our patients seemed to be an extremely highrisk cohort. We believe that a bridging strategy using an external VAD is more rational for elucidating appropriate candidates for durable LVAD, optimizing patients, and determining an appropriate goal for each patient 

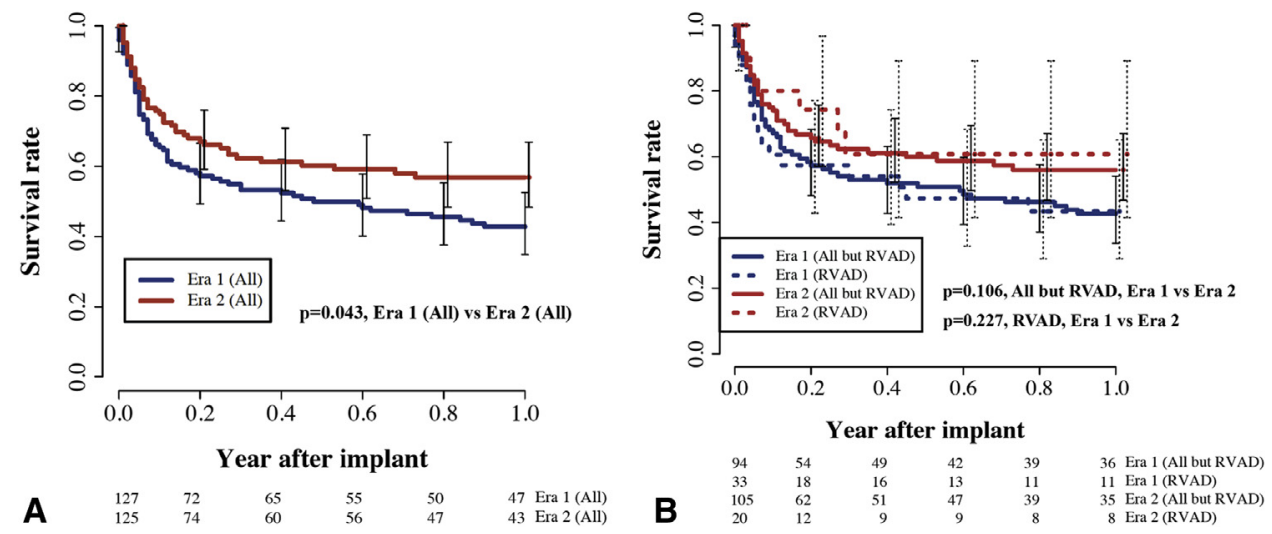

FIGURE 4. A, Comparison of overall survival in Eras 1 and 2. B, Comparison of overall survival in Eras 1 and 2, stratified by isolated RVAD or not. RVAD, Right ventricular assist device.

(ie, recovery, transplantation, or durable LVAD) in this high-risk cohort.

The conventional approach to implanting the CentriMag system requires sternotomy and generally cardiopulmonary bypass use, which limit its applications and may be contraindicated in patients with severe coagulopathy or other relative contraindications to sternotomy. ${ }^{3}$ To overcome these

TABLE 4. Cox regression analysis for hazard of death

\begin{tabular}{lcccc}
\hline \multicolumn{1}{c}{ Variable } & HR & $\begin{array}{c}\mathbf{9 5} \% \mathbf{C I} \\
\text { lower }\end{array}$ & $\begin{array}{c}\mathbf{9 5} \% \\
\text { CI upper }\end{array}$ & $\boldsymbol{P}$ value \\
\hline Univariable analysis & & & & \\
Year of procedure & 0.940 & 0.882 & 1.001 & .055 \\
Age & 1.022 & 1.008 & 1.037 & .002 \\
Female sex & 1.325 & 0.935 & 1.878 & .114 \\
Body mass index & 1.002 & 0.977 & 1.028 & .868 \\
Minimally invasive & 0.860 & 0.516 & 1.432 & .562 \\
Acute myocardial & 0.824 & 0.556 & 1.219 & .332 \\
$\quad$ infarction & & & & \\
Total bilirubin & 1.037 & 1.009 & 1.066 & .008 \\
Creatinine & 1.061 & 0.993 & 1.134 & .079 \\
Lactate & 1.055 & 1.015 & 1.097 & .006 \\
Ventilator support & 1.103 & 0.775 & 1.571 & .587 \\
Multivariable analysis & & & & \\
Year of procedure & - & - & - & - \\
Age & 1.031 & 1.016 & 1.046 & $<.001$ \\
Female sex & 1.608 & 1.121 & 2.306 & .009 \\
Body mass index & - & - & - & - \\
Minimally invasive & - & - & - & - \\
Acute myocardial & - & - & - & - \\
$\quad$ infarction & & & & \\
Total bilirubin & 1.041 & 1.012 & 1.071 & .005 \\
Creatinine & 1.086 & 1.018 & 1.159 & .012 \\
Lactate & 1.072 & 1.030 & 1.116 & $<.001$ \\
Ventilator support & - & - & - & - \\
\hline
\end{tabular}

Mean \pm standard deviation for total bilirubin, creatinine, and lactate: total bilirubin, $3.0 \pm 4.9 ;$ creatinine, $1.8 \pm 2.3$; lactate, $3.9 \pm 3.9 . H R$, Hazard ratio; $C I$, confidence interval. drawbacks, we have developed minimally invasive cannulation techniques, ${ }^{4-6}$ and in 2015, Ec-VAD (Figure 2, B) became our standard transition configuration between peripheral ECMO and durable LVAD. ${ }^{4}$ Major benefits of our Ec-VAD approach are in preventing left ventricular distension, perfusing oxygenated blood from the upper body, unloading both the right and left ventricles efficiently (ECMO may increase LV afterload), mobilizing the patient, removing the oxygenator sooner, and preventing adhesion. Regarding the last point, in patients with conventional BiVAD, we often encountered dense adhesions around the cannula, which certainly increased the surgical complexity when we converted to durable VAD. We found that sparing the sternum greatly facilitates subsequent durable LVAD surgery. For RV failures after durable LVAD implantation, percutaneous RVAD is a more attractive approach, because the majority are temporal phenomena. ${ }^{12,13}$

We found significantly improved in-hospital mortality over time, which also seems to affect better midterm outcomes. A certain degree of reduced mortality was observed predominantly in patients with acute myocardial infarction and myocarditis. We speculate that invisible but important factors attributed are change of our conception with regard to MCS therapy to cardiogenic shock and improvement of patient management. After the Intra-Aortic Balloon Pump in Cardiogenic Shock II (IABP-SHOCK II) trial conferred no benefit of IABP in acute myocardial infarction and cardiogenic shock, ${ }^{14}$ we have adopted aggressive MCS therapy to cardiogenic shock. Furthermore, to streamline care for these critically ill patients, our center established a multidisciplinary Shock Team for patients with acute cardiogenic shock. ${ }^{15}$ We believe this team approach greatly facilitates timely support with both percutaneous and surgical MCSs to avoid the consequences of circulatory collapse.

Finally, it is noteworthy that the effect of era was not independently associated with the risk of death after continuous-flow external VAD implantation, after adjusting 
for other covariates such as total bilirubin, creatinine, and lactate levels (Table 4). Given that the major baseline differences between the 2 eras were in percutaneous MCS, organ function, and lactate (Table 1), we believe it reasonable to stabilize organ functions and tissue perfusion with percutaneous MCS before continuous-flow external VAD implantation. Though there was no clear time point when we switched our strategy, the present study supports our current treatment approach.

This study has several limitations, starting with its design as a retrospective analysis of a single-center experience. Second, because of the nature of single-center studies, the outcomes described here are based on our practice in terms of patient selection, surgery, and management, and our findings might not be applicable to other centers. Third, the analysis between groups was a historical comparison, and so residual bias by unmeasured confounders might still exist. However, because the primary aim of this study was to elucidate the association between temporal changes of practice patterns and improving the outcomes of continuous-flow external VAD implantation, potential historical bias is an inevitable aspect of this study.

In conclusion, the early and late outcomes of continuousflow external VAD implantation for refractory cardiogenic shock were significantly improved in Era 2. These dramatic improvements may be related to our institutional changes in treatment strategies. In the contemporary MCS era, flexibility in the use of both percutaneous MCS and temporary VAD as the situation demands is necessary to treat this seriously ill patient population.

\section{Webcast}

You can watch a Webcast of this AATS meeting presentation by going to: https://aats.blob.core.windows.net/ media/17AM/2017-05-02/RM306/05-02-17_Room306_ 1653_Takeda.mp4.

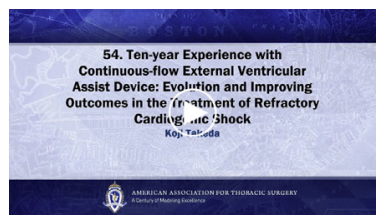

\section{Conflict of Interest Statement}

Dr Naka has received consulting fees from Abbott. All other authors have nothing to disclose with regard to commercial support.

\section{References}

1. Stretch R, Sauer CM, Yuh DD, Bonde P. National trends in the utilization of short-term mechanical circulatory support: incidence, outcomes, and cost analysis. J Am Coll Cardiol. 2014;64:1407-15.

2. Werdan K, Gielen S, Ebelt H, Hochman JS. Mechanical circulatory support in cardiogenic shock. Eur Heart J. 2014;35:156-67.
3. Takayama H, Soni L, Kalesan B, Truby LK, Ota T, Cedola S, et al. Bridge-to-decision therapy with a continuous-flow external ventricular assist device in refrac tory cardiogenic shock of various causes. Circ Heart Fail. 2014;7:799-806.

4. Takeda K, Garan AR, Topkara VK, Kirtane AJ, Karmpaliotis D, Kurlansky P, et al. Novel minimally invasive surgical approach using an external ventricular assist device and extracorporeal membrane oxygenation in refractory cardiogenic shock. Eur J Cardiothorac Surg. 2017;51:591-6.

5. Takayama H, Naka Y, Jorde UP, Stewart AS. Less invasive left ventricular assist device placement for difficult resternotomy. J Thorac Cardiovasc Surg. 2010; 140:932-3.

6. Takayama H, Naka Y, Kodali SK, Vincent JA, Addonizio LJ, Jorde UP, et al. A novel approach to percutaneous right-ventricular mechanical support. Eur J Cardiothorac Surg. 2012;41:423-6.

7. Truby L, Mundy L, Kalesan B, Kirtane A, Colombo PC, Takeda K, et al. Contemporary outcomes of venoarterial extracorporeal membrane oxygenation for refractory cardiogenic shock at a large tertiary care center. ASAIO J. 2015;61:403-9.

8. Ando M, Garan AR, Axom KM, Takeda K. Floating clots in the descending aorta: a rare complication of femoral venoarterial extracorporeal membrane oxygenation combined with microaxial pump for cardiogenic shock. Circ Heart Fail. 2017;10:https://doi.org/10.1161/CIRCHEARTFAILURE.117.004196.

9. Goodman DM. Platelet dysfunction during extracorporeal membrane oxygenation: a new mechanism by which to control bleeding? Crit Care Med. 2000;28:2667-8.

10. Yoshioka D, Takayama H, Garan AR, Topkara VK, Han J, Li B, et al. Bridge to durable left ventricular assist device for refractory cardiogenic shock. J Thorac Cardiovasc Surg. 2017;153:752-62.e5.

11. Adamo L, Nassif M, Tibrewala A, Novak E, Vader J, Silvestry SC, et al. The Heartmate risk score predicts morbidity and mortality in unselected left ventricular assist device recipients and risk stratifies INTERMACS class 1 patients. JACC Heart Fail. 2015;3:283-90.

12. Kazui T, Tran PL, Echeverria A, Jerman CF, Iwanski J, Kim SS, et al. Minimally invasive approach for percutaneous CentriMag right ventricular assist device support using a single PROTEKDuo cannula. J Cardiothorac Surg. 2016;11:123.

13. Yoshioka D, Takayama H, Garan RA, Topkara VK, Han J, Kurlansky P, et al. Contemporary outcome of unplanned right ventricular assist device for severe right heart failure after continuous-flow left ventricular assist device insertion. Interact Cardiovasc Thorac Surg. 2017;24:828-34.

14. Thiele H, Zeymer U, Neumann FJ, Ferenc M, Olbrich HG, Hausleiter J, et al. Intraaortic balloon support for myocardial infarction with cardiogenic shock N Engl J Med. 2012;367:1287-96.

15. Garan AR, Kirtane A, Takayama H. Redesigning care for patients with acute myocardial infarction complicated by cardiogenic shock: the "Shock Team" JAMA Surg. 2016;151:684-5.

Key Words: cardiogenic shock, extracorporeal membrane oxygenation, ventricular assist device, outcome, bridge

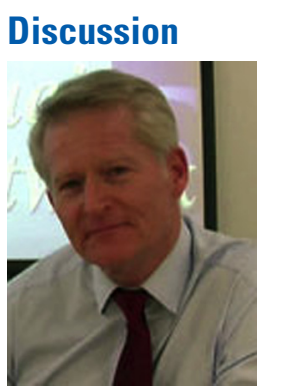

Dr Stephan W. Schueler (Newcastle upon Tyne, United Kingdom). Dr Takeda, thank you very much for providing me with the manuscript and it was a delight to read this. I would like to congratulate you and your colleagues from Columbia for their contribution in the field of acute mechanical circulatory support. Your group has repeatedly demonstrated that for undoubtedly the sickest group of patients it is possible to achieve reasonable results with continuous technical and strategical refinements.

Today you have presented your comprehensive 10-year review with external ventricular assist devices in patients with cardiogenic shock with a detailed reflection on various 
cannulation techniques and surgical approaches in a wide range of cardiogenic shock scenarios. You have shown how to improve early and midterm outcomes and how to reduce adverse events, thus paving a way for future developments in this field.

Within this new framework you have been able to treat significantly more sicker patients, ie, a high number of INTERMACS +1 patients, as opposed to in the first era, which is very remarkable. In addition, in more than $50 \%$ of the patients, or era 2 percutaneous, VA-ECMO was necessary prior to external implant in order to facilitate hemodynamic stability, again, an indication to us that within this era you have treated a sicker group of patients altogether.

Surprisingly, though, which didn't come out in your tables, is that you still had a high application of intra-aortic balloon pumps, which you might want to comment on a little bit later. The spectrum of underlying pathologies leading to cardiogenic shock has not really changed over time significantly, and it comprises the typical range of very sick patients who are referred to most tertiary centers and university hospitals around the world. Despite an increase of the number of sicker patients, you have been able to improve your outcomes, and you have demonstrated this very nicely. Within these different patient groups, the postcardiotomy group still seems to have the highest early mortality. The acute MI-related failure patients seem to show a trend towards improved survival as opposed to the past. Your long-term survival has also significantly improved, up to $57 \%$ at one year in the era 2 respectively, and obviously you have identified a few independent risk factors.

I have the following questions in sequential order. Number one, what is your algorithm for the assessment for patients with questionable neurological status or those who are referred under CPR condition?

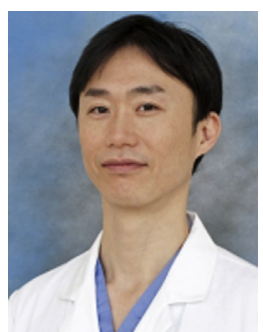

Dr Koji Takeda (New York, NY). For percutaneous devices we have a very low threshold to insert such as ECMO, VA-ECMO. So we do ECPR. If questionable, if we believe the patient has stroke or has hemorrhagic something, we don't put that patient on ECMO.

Dr Schueler. And the same if you have, let's say, outside referrals where you have a questionable downtime?

Dr Takeda. We always ask, but it is always questionable, the answer, so in that case we just wait.

Dr Schueler. Second question. What is your concept of transitioning from external support to a more durable LVAD, particularly if you are not able to wean the RVAD element of your support circuit? I am particularly interested in the timing of this.

Dr Takeda. We stabilize the patient as much as possible with CentriMag. We let the patient walk, patient eat, we won't see the end-organ recovery first, and then off the vent, and then we consider switch to CentriMag, to durable LVAD.

Dr Schueler. But if you still struggle on the RV side, what are you going to do then?

Dr Takeda. We reported last year at the meeting bridge from CentriMag to durable LVAD. As we reported, there is a very high incidence of RV failure.

Dr Schueler. So what do you do with those patients?

Dr Takeda. We switch to a durable LVAD. There is no actual good RVAD. So we keep the CentriMag RVAD.

Dr Schueler. So you put an LVAD in on the left side and you leave the CentriMag system on the right, and then you are aiming for?

Dr Takeda. Recovery, hopefully, but outcomes are not great, actually.

Dr Schueler. So you are kind of aiming for recovery from RV failure? How do you mobilize these patients, how do you get them through this period of recovery after LVAD implant plus leaving the CentriMag in on the right?

Dr Takeda. That's why we came up with this minimally invasive approach. We used to do a BIVAD with open chest, put the full cannula into the heart, and we found very, very tough adhesions around the cannula when we reopened the chest. That's why we save the sternum. Right now we don't open the sternum to support a biventricular patient. We just do a mini thoracotomy and axillary cannulation with femoral venous cannulation.

Dr Schueler. So how do they walk with a femoral venous cannula, because you said they walk?

Dr Takeda. No, no. Let me finish. So once patient comes out from deep shock status, in more than $90 \%$ of cases we can come off the femoral venous cannula, RVAD component. Then we switch to closed ECMO component from mini LVAD axillary configuration, and then patient can walk.

If a patient cannot wean from their femoral venous cannula, we switch to neck. We have a project with your cannula right now.

Dr Schueler. I have one more question. Concerning your various techniques, you could argue that you might as well stay on percutaneous support if there is no problem and avoid the move to an external LVAD and convert from the percutaneous ECMO system directly to a durable device, a philosophy some centers would favor, including myself. In other words, why not refine the percutaneous techniques in the future, which would potentially save you an additional third procedure?

Dr Takeda. I totally agree. The improvement in outcome is driven by technology. So if we have a more durable, powerful percutaneous device, this field is going to be a percutaneous device field. That is what I believe.

Dr Schueler. Thank you very much again, congratulations, and thank you for having me as a discussant. 
Implant numbers trend

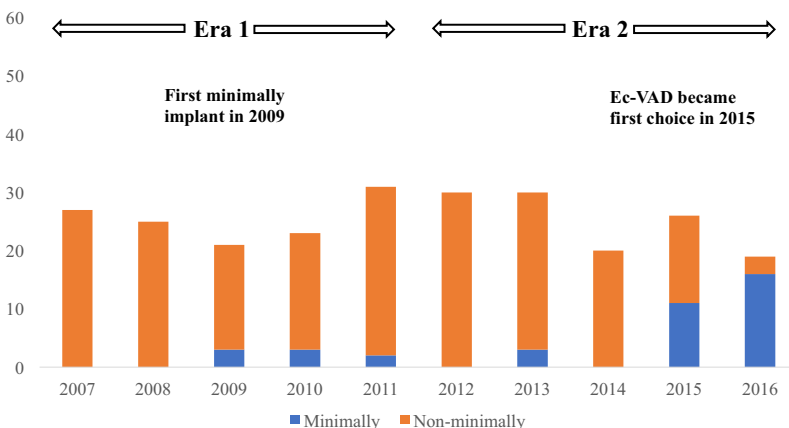

FIGURE E1. Trend of continuous-flow external ventricular assist device over a 10-year periods. Minimally indicates minimally invasive approach. Ec-VAD indicates minimally invasive ventricular assist device implantation with venous cannula from extracorporeal membrane oxygenation support (Figure 2, B). Ec-VAD, Ventricular assist device integrated with extracorporeal membrane oxygenation. 